\title{
ENSAIO BENJAMINIANO: A EXPERIÊNCIA COMO CONSTRUÇÃO DE SENTIDOS
}

\author{
Eduardo Rebuá
}

\begin{abstract}
Falamos exaustivamente de cultura, mas não conseguimos impregnar a rudeza das nossas vidas, nem o mundo em que vivemos, com os valores culturais a que se referem os nossos discursos.
\end{abstract}

[Leandro Konder]

\begin{abstract}
RESUMO
A partir de uma leitura original do conceito de experiência em Walter Benjamin, tendo como lastro, sobretudo, Experiência e pobreza e $O$ narrador, o ensaio empreende um duplo movimento dialético: (i) radiografar a Erfahrung benjaminiana sob perpectivas do tempo-de-agora e (ii) reivindicar a compreensão da experiência como construção coletiva de sentidos, dimensão ontológica basilar e práxis em corrosão na contemporaneidade. Sob a profusão das fantasmagorias na/da modernidade capitalista, intentamos, na tensão mesmo entre o então e o agora, debater elementos da cultura sob o prisma de Benjamin, no esforço de iluminar profanamente o declínio da experiência não como inexorabilidade, mas como sintoma.
\end{abstract}

Palavras-Chave: Benjamin. Experiência. Sentidos. Temporalidade. História

\section{BENJAMIN'S ESSAY: EXPERIENCE AS A CONSTRUCTION OF SENSES}

\begin{abstract}
Starting from an original reading of Walter Benjamin and taking for granted, above all Experiene and Poverty and The Storyteller, the essay includes a double dialetic movement: (i) an x-ray of benjaminian Erfahrung based on present time and (ii) to claim for experience comprehension as colective senses construction, basic ontologic dimension and praxis corrosion in modernity time. Under the great amount of the phantasmagoria in modern capitalist society, we intend, even under tension between the past and the present time, to discuss cultural elements under Benjamin's vision, trying to enlighten profanely the decline of experience not as inexorability but as a system.
\end{abstract}

Key Words: Benjamin. Experience. Senses. Temporality. History 


\section{Benjamin e a experiência como construção de sentidos}

Walter Benjamin talvez seja o pensador marxista mais impertinente de todos, porque indefinível. Um intelectual marginal e um estudioso do misticismo judaico, um outsider da Escola de Frankfurt, um romântico materialista, um ensaísta subversivo. Benjamin produziu uma obra fragmentada, porém originalíssima, que ainda hoje nos ajuda a pensar o mundo concretamente, sob a perspectiva dos vencidos, sem mecanicismos ou fórmulas, num pessimismo revolucionário e, sobretudo, organizado, fonte do método revolucionário de Marx.

Benjamin foi capaz de alçar a cultura a um patamar de destaque no marxismo, extrapolando as fronteiras da filosofia e elaborando um rico mosaico onde a arquitetura, o cinema, a literatura, o judaísmo, a psicanálise estão imbricados, caleidoscopicamente. Deste mosaico benjaminiano, destacamos o que para nós representa a cor mais pujante, a forma mais refinada, a textura mais sensível no trato da relação objetividade-subjetividade: a experiência.

Conforme cita Gagnebin (1999, 8), o conceito de experiência "atravessa toda a sua obra". D'Angelo $(2014,75)$ corrobora a autora quando diz que "o tema é abordado de várias maneiras em textos de diferentes épocas". $\mathrm{Na}$ grande maioria dos estudos (GAGNEBIN, 1999; KONDER, 1999; LÖWY, 2005; AGAMBEN, 2007; MEINERZ, 2008; MITROVITCH, 2011; QUERIDO, 2013; D'ANGELO, 2014, dentre outros) sobre o conceito de experiência em Benjamin - dos mais específicos aos mais gerais - três textos são unanimidade, sendo considerados clássicos: Experiência e pobreza (1933), O narrador (1936) e Sobre alguns temas em Baudelaire (1939).

Meinerz $(2008,12)$ e Mitrovitch $(2011,64)$ convergem quanto à defesa de que o texto de juventude Experiência (Erfahrung), de 1913, representa o primeiro escrito de Benjamin sobre o tema, referenciadas, em Gagnebin (op. cit., p. 8-9). A filósofa suíça radicada no Brasil defende que antes dos textos fundamentais dos anos 1930 há um outro texto onde Benjamin tece comentários a respeito da experiência: Sobre um programa da filosofia do futuro, de 1918. Para ela, as Teses de 1940 finalizam este pentateuco benjaminiano da experiência. Nossa escolha de análise se centrará nos textos Doutor em Educação pela Universidade Federal Fluminense [UFF]. Mestre em Educação pela Universidade do Estado do Rio de Janeiro [UERJ]. Bacharel e licenciado em História pela Universidade Federal Fluminense [UFF]. Brasileiro, residente em Petrópolis-RJ. Email: 
de 1933 e 1936, por entendermos que são mais conhecidos do grande público, mais didáticos no que se refere ao debate sobre a experiência, e finalmente, por já terem sido cotejados, com destaque para as considerações de Jeanne Marie. Experiência e pobreza, junto às teses Sobre o conceito de História, representam, em nossa opinião, a obra-prima de Benjamin. Por sua vez, Jameson (Konder, op. cit., 81) defende que $O$ narrador é o escrito fundamental da obra benjaminiana. Trataremos dos dois a seguir, para em seguida adentrarmos naquilo que entendemos como uma interpretação original nossa: a experiência como construção de sentidos.

\section{0 empobrecimento e o isolamento da experiência}

Experiência e pobreza e $O$ narrador, em uma frase, podem ser definidos como dois tratados distintos porém complementares sobre a experiência: enquanto o primeiro, mais detido ao tema, aborda o empobrecimento da experiência enquanto legado e partilha (BENJAMIN, 2012, 85-86), o segundo cuida do isolamento entre os sujeitos históricos, com a paulatina extinção da arte de narrar (BENJAMIN, 1987, 197). Produzidos com uma diferença de três anos, os dois escritos, que juntos não passam de trinta páginas, diagnosticam de forma precisa um dos males de nosso tempo - para além da primeira metade do século passado, ampliando cada vez mais o conceito de experiência, contra seu uso redutor.

De acordo com Konder $(1999,83)$ Benjamin utilizava Erfahrung para falar do conhecimento adquirido através de uma experiência acumulada, prolongada, desdobrada, num sentido próximo à "viagem" (que em alemão é fahren). Por sua vez, nos textos dos anos 1930, o filósofo marxista retoma a questão da experiência sob uma nova perspectiva: a Erfahrung em oposição à Erlebnis, que corresponde à vivência do indivíduo solitário, privado, isolado. A Erlebnis - e cabe ressaltar que a Erfahrung não a exclui, mas a pressupõe e ultrapassa - é a forte impressão, que exige uma assimilação às pressas e que produz efeitos instantâneos. 
Nos dois escritos a observação de Benjamin sobre a perda da experiência não se altera, uma vez que há, como dissemos, um vínculo semântico-ideológico entre ambos, mas sobretudo, porque há uma dialética fina entre eles: a sociedade capitalista moderna anula as condições de realização da transmissão plena de experiências, o que afeta diretamente a capacidade (arte) de narrar, que não pode prescindir desta transmissão. Com isso, menos narrativas resultam em menos intercâmbio de experiências, e logo, de menos Erfahrung.

Publicado em Praga em dezembro de 1933, alguns meses após os eventos que alçaram o nazismo às rédeas do Estado alemão, Experiência $e$ pobreza lança um aviso de incêndio que ecoaria pelo século XX. Estamos, cada vez mais pobres de experiência! "É uma questão de honra confessar hoje nossa pobreza. Temos de admiti-lo: esta pobreza de experiência não se manifesta apenas no plano privado, mas no de toda a humanidade. Transforma-se assim numa espécie de nova barbárie" (BENJAMIN, 2012, 86).

A sociedade burguesa capitalista moderna nos reduziu a todos a uma situação de pobreza cultural extrema, quando "falamos exaustivamente de cultura, mas não conseguimos impregnar a rudeza das nossas vidas, nem o mundo em que vivemos, com os valores culturais a que se referem os nossos discursos" (KONDER, op. cit., 80). Em outras palavras, de nada serve toda a cultura se não houver uma experiência que nos "ligue" a ela (BENJAMIN, op. cit., 86).

Em nossa leitura Experiência e Pobreza possui três grandes eixos: a parábola do velho em seu leito de morte, a narrativa da monstruosidade da Primeira Guerra e a positividade desta nova barbárie, que nos leva a começar tudo de novo, nos impelindo a construirmos as coisas do início. Transmissão, dissolução, recomeço. Os três distintos momentos dialéticos do texto de 1933 conformam uma sequência de sentido que, se não foi intencional, impregna no leitor um movimento bastante característico da obra benjaminiana que é o manejo da temporalidade: o que passou, o agora, o que virá. Tratando especificamente de cada um destes eixos talvez fique mais nítida esta variedade temporal-semântica. 
A fábula que abre o texto é a de Esopo, intitulada "O velho vinhateiro", ainda que Benjamin não faça referência direta a ela. Surge nos livros escolares alemães desde 1882 e narra a história de um velho pai que, em seu leito de morte, reúne seus filhos e revela que existe um tesouro escondido em sua vinha, cabendo a eles cavar bem fundo para encontrá-lo. Os filhos do vinhateiro cavam dias e noites a fio e não encontraram nada. Todavia, quando o outono se apresentou, a vinha os presenteia com a maior colheita que a região havia visto: "e foi então que os filhos perceberam que o pai lhes legara uma experiência: a bênção não está no ouro, mas no trabalho" (BENJAMIN, op. cit., 85).

Diz Benjamin, em seguida, que a todos nós foram contadas histórias semelhantes, transmitidas experiências como esta, de forma branda ou ameaçadora. Sabia-se perfeitamente o que era a experiência, geralmente com as pessoas mais velhas transmitindo seus conhecimentos e vivências para os mais jovens, através de provérbios, contos, ditados, antes de dormir ou ao redor da mesa, antes ou depois das refeições. Pergunta Benjamin: Para onde isto tudo foi? Onde estão as pessoas capazes de contar uma história de verdade? Um provérbio tem alguma utilidade hoje? A experiência ainda consegue mobilizar a juventude nos dias em que vivemos? A transmissão da experiência é a preocupação basilar de Benjamin na abertura do texto.

Imediatamente após a história de Esopo, o filósofo alemão, em apenas um parágrafo, constrói um relato preciso dos efeitos da Grande Guerra de 1914 sobre a geração que a vivenciou, bem como dos episódios do período Entreguerras, como a Crise de 1929 - e seus efeitos devastadores na Alemanha - bem como a ascensão dos regimes nazifascistas pela Europa. $O$ que chama a atenção na abordagem de Benjamin sobre a dissolução da experiência (cuja "cotação baixou") a partir da barbárie é o fato de chamar a atenção para a mudez dos soldados que voltavam do front, mais pobres de experiência que pudessem ser compartilhadas. Os relatos - e aqui é fundamental a diferença que implicitamente o autor estabelece entre contar algo e partilhar experiências - dos livros do pós-guerra eram "tudo menos experiência contada e ouvida" (Ibidem, 86). Experiência que nunca fora mais 
desmentida: a experiência da estratégia pela guerra de trincheiras, as experiências econômicas pela inflação, as experiências do corpo pela fome, as experiências morais pelos donos do poder. O desenvolvimento maiúsculo da técnica, que forjou a fábrica e o tanque de guerra jogou toda uma geração que poucos anos antes, quando estudantes, ia à escola de carroça; pessoas cuja capacidade de conferir sentido (partilhar experiências) às coisas foi massacrada impetuosamente num lapso de tempo, não lhes restando quase nenhuma referência (pessoas, lugares, histórias), como ilustra Benjamin ao falar das nuvens do céu, única parte da paisagem que se manteve inalterada; uma parte que, todavia, se altera constantemente, não servindo de boa referência, ao contrário das estrelas.

Após a dissolução da experiência na Guerra, identificamos em Experiência e Pobreza um elogio ao recomeço da experiência, quando Benjamin afirma que esta nova barbárie (resultado da pobreza de experiência a nível global) ou nova pobreza impele o bárbaro a ter que "começar tudo de novo, a voltar ao princípio, a saber viver com pouco, a construir algo com esse pouco, sem olhar nem à esquerda nem à direita" (Ibidem, 87). A partir de então Benjamin passa a reivindicar fervorosamente os grandes criadores implacáveis, não os grandes criadores comuns, mas aqueles que começaram de uma prancheta limpa, fazendo tábula rasa; aqueles que foram verdadeiros construtores. Três grandes são citados por Benjamin nesta passagem: Descartes, que na máxima cogito ergo sum compartimentou toda sua filosofia numa única certeza; Einstein, que entendeu que as equações de Newton e as experiências da Astronomia eram os dois "ombros de gigantes" - para nos valermos da famosa frase do cientista inglês se referindo à Galileu e Kepler de onde se erguia sua teoria, para vislumbrar novas possibilidades no campo da Física; e finalmente Klee, por quem Benjamin nutria grande admiração, que assim como outros artistas, se apoiou nos matemáticos para, assim como os cubistas, forjar o mundo a partir de formas estereométricas. Klee se inspirou nos engenheiros, salienta Benjamin, e suas figuras, assim como num "bom automóvel" (onde carroceria e motor atuam juntos como numa sinfonia), 
obedecem, sobretudo, ao que existe em seu interior, mais que na sua interioridade.

Em O narrador, que como dissemos anteriormente está umbilicalmente vinculado à Experiência e pobreza ${ }^{1}$, o diagnóstico de Benjamin sobre a perda da experiência não se altera, ainda que varie sua forma de abordar o tema. A arte de narrar é cada vez mais rara, uma vez que ela depende da transmissão de uma experiência, no sentido pleno. Todavia, as condições para esta transmissão estão cada vez mais escassas na sociedade capitalista de nossa época. Para Benjamin o escritor russo Nikolai Leskov (1831-1895) representaria 0 modelo $^{2}$ de narrador sobre a qual se dedica a descrever no texto de 1936. Um escritor que seria fiel à verdade, atento ao cotidiano e sensível à dimensão prática da existência, um coletador de histórias e experiências em suas viagens pela "Rússia profunda" (aqui vale lembrar a associação entre fahren e Erfahrung). Este tipo de narrador está cada vez mais distante de nós e descrever um Leskov não significa aproximá-lo de nós, mas distanciá-lo, resultado da crise da experiência na modernidade.

Em $O$ narrador identificamos sete momentos-chave da reflexão benjaminiana, especificamente relacionados ao tema da experiência, que nos interessa: (i) o declínio da narrativa como o declínio da faculdade de intercambiar experiências; (ii) a narrativa como uma rede que une as pessoas (e aqui têm destaque os poderosos arquétipos do marinheiro, do camponês e do artífice); (iii) a afirmação da dimensão utilitária da verdadeira narrativa: o narrador como quem aconselha; (iv) a queda na cotação da narrativa como um processo lento e gradual e o romance/informação como formas de comunicação "anti-experiência" (BENJAMIN, 1987, 201); (v) a sociedade burguesa capitalista e a inviabilização da arte de contar; (vi) a memória como a mais épica de todas as faculdades, como a musa da narrativa, dimensão que diminui com a diminuição da narrativa, uma vez que mantém com ela um

\footnotetext{
1 Em O narrador, texto escrito três anos após Experiência e Pobreza, Benjamin reproduz um trecho inteiro, quando afirma a baixa cotação da experiência nos dias atuais e analisa os impactos da Primeira Guerra sobre a geração que a vivenciou.

${ }^{2}$ Franz Kafka (1883-1924), escritor tcheco, representa outra grande referência de Benjamin no estudo da narrativa, sendo para ele o maior narrador da modernidade, tendo escrito sobre 0 autor o ensaio Franz Kafka, Beim Bau der Chinesischen Mauer (Durante a construção da Grande Muralha) (GAGNEBIN, 1987, 18).

Doutor em Educação pela Universidade Federal Fluminense [UFF]. Mestre em Educação pela Universidade do Estado do Rio de Janeiro [UERJ]. Bacharel e licenciado em História pela Universidade Federal Fluminense [UFF]. Brasileiro, residente em Petrópolis-RJ. Email:
} 
vínculo profundo; e finalmente, (vii) a profunda ligação entre a narrativa e o elemento popular, entre o narrador e o povo, entre narrativa e experiência (Ibidem, 214).

A perda da capacidade de trocar experiências (primeiro momento importante do texto) é um ponto de convergência explícito entre $O$ narrador e Experiência e pobreza. Para Benjamin, há uma ligação estreita entre narrar e compartilhar experiências, sendo o narrador, ao mesmo tempo, um "conservador" de histórias e um "compartilhador" de experiências: a "fonte" dos narradores é a experiência que passa de pessoa para pessoa. Assim, a morte da narrativa explica a morte da experiência, assim como seu contrário.

Como apontamos, em Benjamin, a narrativa aparece como uma rede que quando tecida aproxima os sujeitos (segundo momento-chave de $O$ narrador), onde a repetição (contar as histórias de novo) - numa alusão direta à arte de fiar, de tecer materiais - desempenha um papel primordial na composição do ritmo e na garantia da conservação/permanência daquelas histórias no tempo, histórias forjadas artesanalmente, uma vez que a narrativa corresponde a uma forma artesanal de comunicação. Os tipos arcaicos fundamentais da narrativa, para o pensador marxista, eram o marinheiro comerciante, que viaja por lugares vários e coleta histórias e impressões as mais diversas; o camponês sedentário, que não conhece outros lugares fora de seu mundo, e que por isso maneja a tradição e os costumes como ninguém; e finalmente, aquele arquétipo que provoca a interpenetração dos outros dois: 0 artífice - oriundo do sistema corporativo medieval -, "artista da mão" (artesão), que apara as arestas e burila a narrativa nascida de seus dois pais, o marinheiro e o camponês. O filme Narradores de Javé3 (2003), de Eliane Caffé, retrata bem o caráter artesanal da verdadeira narrativa, que é sempre uma obra coletiva, em aberto e fundamentalmente oral, como diz Benjamin, quando afirma que entre as narrativas escritas, as melhores são as que menos se distinguem das histórias orais. No filme, o personagem Antônio Biá, um mentiroso patife incumbido pelo povoado ameaçado de extinção de escrever a história de Javé (por ser o único alfabetizado), ao coletar as histórias e

\footnotetext{
${ }^{3}$ NARRADORES DE JAVÉ. Direção: Eliane Caffé. Produção: Lumiere/ Vídeofilmes, 2003. 102 min. Son, Color, Formato: $16 \mathrm{~mm}$.

Doutor em Educação pela Universidade Federal Fluminense [UFF]. Mestre em Educação pela Universidade do Estado do Rio de Janeiro [UERJ]. Bacharel e licenciado em História pela Universidade Federal Fluminense [UFF]. Brasileiro, residente em Petrópolis-RJ. Email:
} 
"causos" das pessoas daquela vila pobre do nordeste, afirma: "uma coisa é o fato acontecido, outra é o fato escrito". E acrescentaríamos, atualizando Biá para a perspectiva benjaminiana, que uma coisa é o fato acontecido, outra é o fato narrado e "experienciado" pelo ouvinte, um reprodutor em potencial daquilo que ouviu, ou como diz Benjamin, aquele que tem interesse em conservar o que foi narrado. Ainda que entre o acontecido e o narrado, como o dito popular, existam outros tantos contos.

O terceiro momento-chave de $O$ narrador está na afirmação da dimensão utilitária da narrativa, que sempre tem algo a dizer - seja através de um ensinamento moral, de uma sugestão prática ou de um provérbio -, ou em outras palavras, alguma sabedoria para ser transmitida. O narrador é quem aconselha, logo, a morte da narrativa sepulta consigo o conselho, a experiência comunicável, a sabedoria: "aconselhar é menos responder a uma pergunta que fazer uma sugestão sobre a continuação de uma história que está sendo narrada" (BENJAMIN, 1987, 200). O provérbio, ideograma da narrativa e/ou ruína de alguma, segundo Benjamin, é um termômetro importante para medirmos a decadência da sabedoria narrativa e da narrativa da sabedoria. $\mathrm{Na}$ contemporaneidade o provérbio é substituído pelo slogan, "provérbio de uma humanidade que perdeu a experiência” (AGAMBEN, 2005, 10).

Em $O$ narrador, Benjamin utiliza a metáfora da transformação da crosta terrestre (lenta, gradual, da longa duração) para analisar o processo de nascimento, desenvolvimento e ocaso da narrativa, desde a Antiguidade até os nossos dias (momento-chave iv). A queda na cotação da narrativa não foi para o crítico alemão algo abrupto, tampouco isolado, ou seja, sem o florescimento de outras formas de comunicação que concorreram, desigual e combinadamente (na epopeia, por exemplo, onde não há uma indiferenciação entre narrativa e romance), com a narrativa, tendo destaque para o romance, filho da Idade Moderna, e a informação, filha da Idade Contemporânea, formas de comunicação que, diferentemente da narrativa, não têm na experiência sua fonte fundamental. O romance está profundamente vinculado ao livro (e sua difusão só é possível com a invenção da imprensa); não procede da oralidade (tampouco a alimenta), como os contos, lendas, sagas, fábulas, novelas; 
segrega (sua origem é o indivíduo isolado, que não recebe conselhos, solitário), ao contrário da narrativa, que é um processo coletivo (onde quem escuta uma história está em companhia do narrador); é avesso à sabedoria (Dom Quixote indicaria que a grandeza de caráter, a coragem e a generosidade do cavaleiro mambembe são profundamente refratárias ao conselho e despossuídas de sabedoria, com o herói comovendo pelo riso e pela pena, mas não sendo capaz de transmitir sabedoria e experiência com seus feitos); corresponde aos anseios e expressões artísticas da ascendente burguesia europeia (sendo até hoje hegemônico como expressão estética da narrativa escrita); é repleto de conotações psicologizantes, do escritor e do leitor (enquanto a narrativa é simples e direta); tem como preocupação principal a busca do sentido (da vida, da morte, da história), separando o sentido e a vida, o essencial e o temporal, enquanto a narrativa tem como núcleo central a moral da história; é norteada pela tensão (a necessidade de devorar a substância lida) e tem um final (materializado no The End) característico dos finais de livros e/ou filmes, enquanto na narrativa o desfecho não se encerra num final imediato.

A informação jornalística ameaça o romance, provocando nele uma crise. Sua rotina é falar de acontecimentos diminutos, de micro-fatos, de assuntos desconexos, descontextualizados, autoexplicativos, assépticos, que exigem uma verificação instantânea, no exato momento em que são lidos. A informação é ré no processo que trata da extinção da arte da narrativa. Uma história de mil anos não importa mais que um atropelamento na esquina de nossas casas; uma revolução tem menos importância que o próximo escândalo envolvendo aquele deputado corrupto; uma biografia ou um povo não têm condições de competir com as manchetes do noticiário policial, que funcionam como numa linha de montagem fordista; o novo de hoje é apenas o obsoleto da manhã seguinte. Benjamin, a partir de Valéry, vai dizer que o homem de hoje não cultiva o que não pode ser abreviado, fazendo com a narrativa o mesmo.

O romance se apresenta, junto à informação jornalística, no momento em que a experiência coletiva entra em ruína, como formas narrativas que se colocam como hegemônicas: "os dois têm em comum a necessidade de 
encontrar uma explicação para o acontecimento, real ou ficcional. A informação deve ser plausível e controlável; já o romance parte da procura do sentido (...)" (GAGNEBIN, 1987, 14).

O quinto momento significativo da argumentação de Benjamin, no texto que analisamos, diz respeito à reflexão sobre a consolidação da sociedade burguesa capitalista e o consequente sepultamento, sempre inconcluso, da arte de contar. As condições de realização do processo de transmissão de experiências, na contemporaneidade, são extremamente adversas, dada a velocidade de expansão do capitalismo e do desenvolvimento da técnica, que alteram rapidamente as condições de vida dos seres humanos e, logo, sua capacidade de assimilação. De acordo com Gagnebin (op. cit., 10), Benjamin distingue, dentre estas condições, três principais: a inviabilidade da comunidade (de discurso e de vida) - condição imprescindível para a comunhão de experiências (entre narrador e ouvinte) -, somada a uma separação cada vez mais impetuosa entre os grupos humanos (sobretudo entre as gerações, a despeito das tecnologias, que nos aproximaram nos separando); a decadência do trabalho manual (o artesanato em especial, com seus ritmos orgânicos e mais lentos), por conta do avanço impetuoso do industrialismo, que acelera a produção e a vida, sedimentando as experiências e afastando os sujeitos da possibilidade de intercambiar suas impressões, sonhos, vivências; e finalmente, o fim dos conselhos, da moral da história de cada biografia, individual e/ou coletiva, da sabedoria como legado e como substância da vida social - o indivíduo isolado, desorientado e desaconselhado vai buscar o seu duplo no herói do romance, solitário como ele.

Outro ponto importante da argumentação de Benjamin no texto é seu olhar sobre a memória (sexto momento-chave), que seria "a mais épica de todas as faculdades". Com o ocaso do intercâmbio de experiências, uma das consequências mais imediatas é a supressão da memória, individual e coletiva, e a perda do sentido da história (MEINERZ, 2008, 42). Como dissemos anteriormente, o que mantém o narrador (que é capaz de guardar e contar muitas histórias pois as conhece integralmente, uma vez que as viveu e/ou ouviu) e ouvinte é o interesse em conservar o que foi narrrado. Por sua vez, o 
romancista e sua experiência fragmentada está impedido de conhecer histórias e, logo, de guardar a memória.

Em Benjamin memória e experiência estão intimamente imbricados, porque mantêm entre si uma relação de interdependência. Só é possível reviver, restabelecer experiências passadas através da memória (fixando-as, retendo-as, reconhecendo-as, evocando-as), que só se fixa através da experiência, no sentido da Erfahrung e não da Erlebnis - sem vínculos com o passado, efêmera, desconexa, isolada -, tônica do cotidiano que vivenciamos. Um mundo sem experiências partilháveis, fragmentado, mudo, norteado pela efemeridade do instantâneo, não precisa da memória, pois não há o que ser revivido. Se perece a experiência perece também a memória e, por conseguinte, a tradição.

Meinerz (op. cit., 70) compara dois escritos de dois escritores latinoamericanos fundamentais, Borges e Gabriel García Márquez. O conto Funes, o memorioso, que narra a história de Irineu Funes, um jovem que ficara paralítico e que após o trauma desenvolve uma memória prodigiosa, que catalogava todas as imagens da memória; e Cem anos de solidão, que narra a história de um mítico povoado colombiano onde em um dado momento todos os habitantes são acometidos por um esquecimento coletivo, provocado por um surto de insônia que se alastrou como uma peste. Para a autora a comparação é um aviso sobre o perigo do excesso e da falta. A memória em demasia de Funes tornava o jovem escravo dos acontecimentos vividos e incapaz de pensar; a falta de memória em Macondo originava uma idiotice sem passado, apagando as marcas construídas por aquelas pessoas no tempo. Esquecer e lembrar - e o esquecimento é correlato da experiência - deve ser um jogo salutar entre reter e deixar partir, entre guardar e apagar, permitindo que memórias continuem seu ciclo de nascimento e morte, parteiro da experiência. Num mundo cada vez mais veloz, há pouco espaço para a memória, para contar, para experienciar coisas, onde a informação jornalística representa exemplo paradigmático. Tudo se torna antiquado em pouco tempo: o jornal estampado na banca hoje, embrulhará o peixe na feira de amanhã. Finalizando, para o filósofo, um acontecimento vivido é finito, terminado na 
esfera do vivenciado, enquanto que o que é lembrado é sem limites, uma vez que é uma chave para tudo que o antecede e que o sucede (BENJAMIN apud GAGNEBIN, 1987, 15). Em outras palavras, podemos dizer que a Erfahrung é mais que a Erlebnis, pois a experiência, profundamente vinculada à memória, fixa aquilo que a vivência deixa passar.

Finalmente, o sétimo e último momento-chave da reflexão de Benjamin em $O$ narrador corresponde à explicitação, presente em todo o texto, da forte ligação entre a narrativa e o popular, entre narrador e povo, ou numa mirada ampla, entre narrativa e experiência, nosso foco neste garimpo pelo famoso escrito de 1936 sobre Leskov e a narrativa. Parafraseando Gorki, Benjamin afirma que Leskov é o escritor enraizado no povo de forma mais profunda, sendo o mais "puro" de influências vindas de fora da Rússia: "o grande narrador tem sempre suas raízes no povo, principalmente nas camadas artesanais” (BENJAMIN, 1987, 214). Estar enraizado no povo significa nutrir-se de uma fonte inesgotável de experiência, viva porque compartilhada, tangível porque fixada na memória, individual e coletiva. Significa também mover-se para cima e para baixo, do global ao local, com destreza, galgando os degraus da experiência. A partir da metáfora do artesanato (lembrando o artífice como unificador dos arquétipos do marinheiro viajante e do camponês sedentário) é possível dizermos que a oralidade está para o artesanato, assim como a narrativa escrita, está para a atividade fabril. Enquanto o primeiro se alicerça na prática e parte dela, num movimento contínuo onde o tédio, como rotina, é o "chocador dos ovos da experiência", o segundo tem na fragmentação e na perspectiva do isolamento (quem não ouve não é capaz de contar) individual, seu substrato. A metáfora da narrativa como artesanato - tratando especificamente de Leskov e sua narrativa verdadeira - também busca dar conta da dimensão prática da autêntica narrativa, rica em sua concretude, repleta de significado porque parte dos contornos e dos sentidos forjados no real e a partir dele.

O próprio Leskov entendia a narrativa, esta arte artesanal, como um ofício manual, chegando a afirmar numa carta que a literatura não era para ele uma arte, mas um trabalho manual. Não à toa, salienta Benjamin, Leskov 
sentia-se atraído pelo trabalho manual e avesso à técnica fabril. Todavia, no final do texto, o filósofo salienta numa passagem belíssima, a partir de Valéry, que a narração não é produto exclusivo da mão, mas é uma coordenação sensível da alma, do olhar e da mão, assim como o trabalho do artífice, que não se resume simplesmente ao manual. Paripassu com o desaparecimento da mão, no trabalho produtivo, ocorre seu desparecimento na narração. De acordo com Benjamin é possível ir além e perguntar: a relação entre o narrador e sua matéria, a vida humana, não seria também uma relação artesanal? "Não seria sua tarefa trabalhar a matéria prima da existência - a sua e a dos outros transformando-a num produto sólido, útil e único?” (BENJAMIN, op. cit., 221).

A seguir, retomaremos à questão central para nós, a compreensão da experiência como construção de sentidos. Antes, numa imagem de pensamento (Denkbild) livre, inspirada no marxista da melancolia, defendemos que na tessitura coletiva dos fios da experiência, a agulha da narrativa - que tem no tempo da memória sua costura - forja um tecido cuja matéria é a vida humana.

\section{A experiência como construção de sentidos}

$\mathrm{Na}$ análise de dois dos escritos mais importantes de Benjamin Experiência e pobreza e $O$ narrador - buscamos identificar como aparece o conceito de experiência, com quais categorias se conjuga, quais os diagnósticos que apresenta sobre nosso tempo e em que medida fornece pistas para aqueles que insistem em não aceitar a extinção da Erfahrung e a legitimação inexorável da Erlebnis. Não é novidade a discussão do conceito de experiência na obra benjaminiana. Destacamos dois, dedicados especificamente ao tema: "Concepção de experiência em Walter Benjamin", dissertação de mestrado de Andréia Meinerz, e "Experiência e formação em Walter Benjamin”, obra de Caroline Mitrovitch, resultado de sua dissertação de mestrado, de mesmo título.

Analisando os diversos trabalhos que de forma mais detida ou menos interessada abordam o tema da experiência em Benjamin identificamos de 
forma implícita, em alguns textos, indícios de/para uma possível releitura do conceito, que a despeito de não estar presente nos autores estudados - mesmo em seus intérpretes mais importantes, como Jean Marie Gagnebin (1999) e Leandro Konder (1999) -, é perfeitamente sintonizada com a perspectiva benjaminiana da Erfahrung. Tais indícios nos levaram a defender que a experiência em Benjamin pode ser compreendida como um processo, complexo, dinâmico, dialeticamente individual e coletivo, de construção de sentidos.

O mundo tal como se apresentava no início do século passado, herdeiro do XIX e reflexo das transformações no mundo da produção e da vida cotidiana, sob a direção e o domínio da burguesia capitalista, representava, na visão de Benjamin, uma catástrofe em permanência, descrita no mais conhecido e citado texto do filósofo, a IX Tese Sobre o conceito de História (1940).

Em meio às ruínas - diria Benjamin - está o escombro da experiência, o que restou dela. A catástrofe permanente sepulta não apenas os homens e mulheres, os jovens e os velhos, o passado e o presente, mas leva consigo também a capacidade de partilharmos saberes, práticas, subjetividades, sentimentos, mas sobretudo, nossa capacidade de conferir sentido ao que nos acontece. Nossa pobreza, efeito direto da "nova barbárie" cotidiana do mundo forjado pela burguesia à sua imagem e semelhança, é principalmente uma pobreza da experiência, da capacidade de construir sentidos sobre o real. Mais uma vez, é a frase paradigmática de Benjamin a fotografia precisa de nossa época: "Na verdade, de que nos serve toda a cultura se não houver uma experiência que nos ligue a ela?" (BENJAMIN, 2012, 86). E acrescentaríamos: de que vale toda a cultura se ela não fizer sentido?

"Experienciar" em Benjamin significa construir, partilhar e recuperar sentidos sobre a própria existência e sobre o mundo. Em sua abordagem sobre a educação, Mitrovitch $(2011,22)$ defende que é possível pensar no par "experiência/sentido" quando da análise e do uso deste conceito tão caro ao pensamento benjaminiano. Por sua vez, Konder $(1999,26)$ entende que para Benjamin era imperioso desenvolver um conceito superior de experiência, 
capaz de fugir da abstratividade da oposição entre sujeito e objeto; "um conceito de experiência capaz de corresponder às necessidades humanas de uma existência plena de sentido". Em seus escritos sobre Goethe, o próprio Benjamin aborda o vínculo entre experiência e sentido, quando afirma que "a experiência é carente de sentido e espírito apenas para aquele já desprovido de espírito" (BENJAMIN, 2009, 23).

É importante frisar que a experiência benjaminiana está voltada para o coletivo (MITROVITCH, op. cit.,126-127), numa dialética entre o homem e o mundo, norteada pelo contexto social e pelas condições materiais e subjetivas de cada época histórica. E se a experiência é coletiva, logo, a construção de sentidos é, fundamentalmente, também um processo coletivo, assim como difuso, irregular, multifacetado e histórico. A experiência legada pelo velho vinhateiro à sua prole ou a mudez diante da monstruosidade da Grande Guerra em Experiência e pobreza, bem como a transmissão da experiência pelos artífices das palavras ou das coisas em $O$ narrador, representam processos coletivos de partilha/rememoração de experiências, de construção de sentidos - no plural, uma vez que não são representações unívocas, singulares sobre o mundo - forjados a partir da alteridade e das contradições do real concreto. Defendemos que "sentido", no singular, pode dar a ideia do sentido unívoco do romance, ou seja, da busca de "uma" explicação para a vida, a morte, a história: o sentido como fim. Falamos de sentidos, no plural, como significações, individuais e/ou coletivas, concepções de mundo, impressões sobre o mundo, forjadas e ressignificadas cotidianamente a partir da (s) experiência (s) partilhada com o (s) outro (s), mas abertas e não fechadas como fim: o sentido como o "sendo" (processo).

Os ensaios dos anos 1930 (Sobre alguns temas em Baudelaire também poderia constar nesta lista), de uma maneira geral, constituem uma tentativa de pensar o fim da experiência e a possibilidade de sua reconstrução, a partir da ruína. Este resgate do sobrevivente em meio aos escombros indica que há esperança de um novo hoje, num tempo-de-agora (Jetztzeit) - ponto de partida benjaminiano, o momento do despertar - que se articule com a retomada crítica do passado e aponte para um futuro que não está escrito e que por isso 
não consagrou de forma definitiva a barbárie. Resgatar o corpo da experiência com vida significa garantir, através da "dialética da ruína benjaminiana" (MITROVITCH, op. cit., 166), o mergulho no caos da cultura moderna em busca de novos sentidos para o cotidiano em frangalhos.

A história a contrapelo de Benjamin legitima uma concepção de história que é abertura (LÖWY, 2005, 147) - onde o "novo" é possível - e não fechamento; que é imprevisibilidade e não fatalismo; uma história não de uma temporalidade uniforme, mas de múltiplos tempos, interpretações e sentidos, atravessada pelo conflito. No que Löwy chama de marxismo da imprevisibilidade, Benjamin apresenta uma história aberta que significa, num viés político, possibilidade e não inevitabilidade, tanto da hecatombe quanto da emancipação. Esta última representa uma aposta do pensador, ainda que o termo não esteja presente em seus escritos. Aposta que traduz a incerteza de um futuro que não seja a barbárie, mas que ao mesmo tempo explicita que o trem que ruma para o abismo ainda não chegou lá, podendo ser freado pela ação emancipadora-revolucionária, que aparece no autor muitas vezes como um intento desesperado para evitar o despenhadeiro.

O intelectual que conferiu um sentido político para a melancolia ${ }^{4}$ lançou um aviso de incêndio que pode ser traduzido no axioma "a catástrofe é possível se não provável - a não ser que [...]" (LÖWY, op. cit., 152). Se a história é abertura e não fechamento e se a experiência não desapareceu da face da Terra, a despeito de sua cotação cada vez mais baixa, é possível afirmarmos que há em Benjamin a defesa intransigente da abertura de sentido sobre as temporalidades humanas (passado, presente e futuro) e, logo, das novas significações sobre o mundo.

\section{CONCLUSÃO}

\footnotetext{
4 Entendida não como patologia, mas como sensibilidade ao mesmo tempo incapaz de se adaptar e capaz de captar/sofrer, sinalizando aquilo que não vai bem na cultura, no mundo real, como afirma Maria Rita Kehl em debate realizado em São Paulo (outubro de 2013), em parceria com Michael Löwy e organizado pela Boitempo. Disponível em: http://acasadevidro.com/2014/01/25/maria-rita-kehl-e-michael-lowy-debatem-walter-benjamin-eo-capitalismo-como-religiao/ . Acesso em: dez. 2015.

Doutor em Educação pela Universidade Federal Fluminense [UFF]. Mestre em Educação pela Universidade do Estado do Rio de Janeiro [UERJ]. Bacharel e licenciado em História pela Universidade Federal Fluminense [UFF]. Brasileiro, residente em Petrópolis-RJ. Email:
} 
Reconstruir o sentido da Erfahrung em meio a um cotidiano fragmentário e aparentemente sem sentido é obrigatoriamente restituir a capacidade de dar sentido e acrescentar significação à existência, tendo em vista que a História "é construção de sentidos que se entrecruzam com as urgências do presente" (MITROVITCH, 2005, 4), sentidos que não se localizam apenas nos sujeitos isolados, na realidade concreta ou no imaginário/simbólico, mas nesta articulação.

Compreender a experiência como construção de novos/outros sentidos; como a elaboração coletiva de pontes que nos liguem à cultura; como a forja de histórias/narrativas que significam algo porque são tecidas de forma partilhada, pelos grandes-pequenos criadores implacáveis, que recomeçam o ciclo do novo a despeito das bombas-relógio das novas formas de barbárie que amedrontam e dilaceram. Tudo isso representa a defesa intransigente e otimista da inventividade, da capacidade humana de construir uma existência plena de sentido, mesmo na contramão.

Passadas mais de sete décadas da morte de Benjamin, o panorama cultural, político, econômico e social do século XX e do agora só confirma a sensibilidade e a radicalidade de seu pensamento, capaz de identificar, em meio a tantas outras interpretações, (filosóficas, históricas, religiosas, psicológicas etc., um "outro sintoma" (ŽIŽEK, 2010, 57) de nossa época, de longa permanência e por isso assustadoramente atual: somos cada vez menos capazes de partilharmos experiências, de contarmos histórias de verdade, de conferirmos sentidos à vida. A depressão, também chamada de "doença do século", se entendida como um "sentimento social mais geral", como afirma a psicanalista Maria Rita Kehl ${ }^{6}$, vincula-se profundamente com a perda de

\footnotetext{
5 De acordo com Žižek, a partir de Lacan é possível compreender que Marx é o "pai" do sintoma, cuja descoberta deve ser buscada na maneira como o filósofo alemão concebeu a transição do feudalismo para o capitalismo: o estabelecimento da sociedade de matiz burguesa "recalcou" as relações de dominação/servidão, fazendo com que formalmente pareçamos estar lidando somente com sujeitos livres, "isentos" de fetichismo. A permanência do par dominação/servidão emerge num sintoma que subverte a aparência ideológica de liberdade, igualdade e outros "universalismos" burgueses: "Esse sintoma, o ponto de emergência da verdade sobre as relações sociais, são precisamente as 'relações sociais entre as coisas': 'Em vez de aparecer em quaisquer circunstâncias como suas próprias relações mútuas, as relações sociais entre os indivíduos disfarçam-se soba forma de relações sociais entre as coisas' (...)" (Ibidem).

${ }^{6}$ Palestra no programa Café Filosófico CPFL, gravada no dia 24 de junho de 2009, em São Doutor em Educação pela Universidade Federal Fluminense [UFF]. Mestre em Educação pela Universidade do Estado do Rio de Janeiro [UERJ]. Bacharel e licenciado em História pela Universidade Federal Fluminense [UFF]. Brasileiro, residente em Petrópolis-RJ. Email:
} 
sentido - das coisas, do trabalho, das relações, da vida, do mundo -, num processo quase epidêmico de vazio interior, que em nosso entendimento, está estreitamente ligado à perda da experiência, compreendida como construção coletiva de sentido.

\section{REFERÊNCIAS}

AGAMBEN, Giorgio. Infância e história: destruição da experiência e origem da história. Belo Horizonte: Editora UFMG, 2005.

Infancia y historia: destrucción de la experiencia y origen de la historia. Buenos Aires: Adriana Hidalgo Editora, 2007.

BENJAMIN, Walter. "O narrador". Considerações sobre a obra de Nikolai Leskov. In: Magia e técnica, arte e política: ensaios sobre literatura e história da cultura (Obras escolhidas v. 1). São Paulo: Editora Brasiliense, 1987. p. 197-221.

Duas Cidades: Editora 34, 2009.

Ensaios reunidos: escritos sobre Goethe. São Paulo: "Experiência e pobreza". In: O anjo da história. Belo Horizonte: Autêntica Editora, 2012. p. 83-90.

drogas. Belo Horizonte: Autêntica Editora, 2013a.

Rua de mão única: Infância berlinense: 1900. Belo Horizonte: Autêntica Editora, 2013b.

D'ANGELO, Martha. "Notas sobre os conceitos de experiência e história em Walter Benjamin". In: SEMERARO, Giovanni \& D'ANGELO, Martha. Filosofia da História. Niterói: UFF, 2014. p. 75-108.

GAGNEBIN, Jeanne Marie. História e narração em Walter Benjamin. São Paulo: Editora Perspectiva, 1999.

KONDER, Leandro. Walter Benjamin: o marxismo da melancolia. Rio de Janeiro: Civilização Brasileira, 1999.

LÖWY, Michael. Walter Benjamin: aviso de incêndio: uma leitura das teses "Sobre o conceito de história. São Paulo: Boitempo, 2005.

Paulo. Disponível em: https://www.youtube.com/watch?v=gGjPmVTliCk . Acesso em: dez. 2015.

Doutor em Educação pela Universidade Federal Fluminense [UFF]. Mestre em Educação pela Universidade do Estado do Rio de Janeiro [UERJ]. Bacharel e licenciado em História pela Universidade Federal Fluminense [UFF]. Brasileiro, residente em Petrópolis-RJ. Email: 
MEINERZ, Andréia. Concepção de experiência em Walter Benjamin. Dissertação de Mestrado. Rio Grande do Sul: Programa de Pós-Graduação em Filosofia - UFRGS, 2008.

MITROVITCH, Caroline. Experiência e formação em Walter Benjamin. São Paulo: UNESP, 2011.

QUERIDO, Fabio Mascaro. Fetichismo e fantasmagorias da modernidade capitalista: Walter Benjamin leitor de Marx. Revista Outubro, n. 21, $2^{\circ}$ semestre 2013, p. 219-240. 